\title{
Comparative Study of Fuzzy Inference System and Design of Experiment for Clean Room Equipment Factory
}

\author{
Prasert Aengchuan and Pasura Aungkulanon
}

\begin{abstract}
The clean room's performance can extremely improve by eliminating surface particle from materials or parts before entering the clean area. Due to the inconsistency of air velocity of nozzles, so a method that can deal with uncertainty should be implemented. In this study, the comparison of fuzzy inference system (FIS) and design of experiment (DOE) was purposed with the air shower pass box (ASPB) production process of the clean room company in Thailand. The objective was to find out the appropriate factors to increase air velocity of nozzles. FIS was determined and displayed by linguistic terms. Then, the created fuzzy rules were used to extract the fuzzy inputs which consisted of air box thickness, nozzle orifice diameter, blower's company, and angle of welding. $2^{\mathrm{k}}$ factorial DOE was utilized with these four input factors. Analysis of variance was used to analyze of 3 replications of air velocity of nozzles. The results showed that the FIS model obtained better performance than DOE model for this application. The most appropriate levels of setting achieved by the FIS model by setting the thickness of the air box at $300 \mathrm{~mm}$, nozzle orifice diameter of $27 \mathrm{~mm}$, blower from company A, and angle of welding at 62 degrees. These levels of setting are applied to use in the production design process of the company.
\end{abstract}

Index Terms-FIS, DOE, air shower pass box, clean room.

\section{INTRODUCTION}

Nowadays, all factories need to be well-managed and employees need to realize about losses initiating in many activities. Productivity improvement needs to be considered in order to increase production efficiency. Losses such as overproduction, late deliveries, high inventories, high defects have effected to customer satisfaction. Factories are required to have proper knowledge of loss management. The clean room factory is mainly a highly sanitary room without larger particles, with electrostatic discharge control in instruments and machines and controlled temperatures and humidity throughout all 24 hours. Beginning equipment that is important to control the amount of dust attached to work pieces or raw materials used in production before entering a clean room is the air shower pass box, a device for blowing clean air through an air filter system using high efficiency particulate air (HEPA) filters, making the output wind clean and sufficiently forceful for blowing dust from parts or materials [1]. There are some previous literatures described how to qualify clean room system [2]. This study was

Manuscript received August 30, 2018; revised January 22, 2019.

Prasert Aengchuan is with the School of Manufacturing Engineering, Institute of Engineering, Suranaree University of Technology, Nakhon Ratchasima, Thailand (e-mail: prasert.a@sut.ac.th).

Pasura Aungkulanon is with the Department of Industrial Engineering, Faculty of Engineering, Srinakharinwirot University, Nakhon nayok, Thailand (e-mail: pasurachacha@hotmail.com). conducted with the company that manufactures clean room equipment in Thailand. Production systems are composed of the design and planning section, the cutting section, the bending section, the sub-assembly section, the finished assembly section, the powder coating section, the electrical section, and installation work. The aforementioned problem has a direct impact on production quality and credibility. The consequences are delayed deliveries due to the need to replace equipment. A problem affecting company's image is the air velocity of nozzle lower than the set value in engineering designs during installation. Due to the inconsistency of air velocity of nozzles, the comparative study of the FIS and DOE was purposed to find out the appropriate factors to increase air velocity of nozzles.

\section{FUZZY INFERENCE SYSTEM AND APPLICATIONS}

The original structure of FIS is shown in Fig. 1. Generally FIS can be classified into three types: Mamdani, Sugeno and Tsukamoto [3]. The unlike between Mamdani and Sugeno relies on the consequence of fuzzy rules. While Mamdani utilizes fuzzy sets as rule consequence, Sugeno utilizes linear functions as rule consequence. For Tsukamoto, the consequence of each fuzzy rule uses a monotonic membership function. For this study, Mamdani is selected. The important steps to generate FIS are: transforming crisp inputs to be fuzzified inputs, fuzzification of the fuzzy inputs, creating of the rule base and defuzzification by transforming the fuzzified output to be the crisp output value. FIS is applied in various applications [4]-[6].

For this study, four input factors, air box thickness $\left(A_{i}\right)$, nozzle orifice diameter $\left(B_{i}\right)$, blower company $\left(C_{i}\right)$ and angle of welding $\left(D_{i}\right)$ were applied as the inputs of the FIS. All four fuzzy inputs represented by membership functions, $\mu_{A_{i}}, \mu_{B_{i}}, \mu_{C_{i}}$ and $\mu_{D_{i}}$, respectively. The output variable was air velocity of nozzles $\left(V_{i}\right)$, represented by membership functions, $\mu_{V_{i}}$. A fuzzy logic toolbox of MATLAB was utilized to the clean room FIS to calculate air velocity of nozzles. The clean room FIS is shown in Fig. 2. The universe of discourse, membership functions, linguistic values of each variable of fuzzy inputs and fuzzy output are displayed in Table 1.

The IF-THEN fuzzy rules are sequentially generated. A set of fuzzy rules is advised by expert's knowledge, relied on each intrinsic situation. Each rule is assessed by FIS according to the level of input data that compatible to rule constraint. Due to the output, air velocity of nozzles is fuzzy sets, Mamdani type is applied for assessing and compiling the fuzzy rules. The fuzzy rules can be described by Cartesian 
product of the fuzzy inputs, $x_{1} \times x_{2} \times x_{3} \times x_{4}$ [7].

The relationship between air box thickness $\left(x_{1}\right)$, nozzle orifice diameter $\left(x_{2}\right)$, blower's company $\left(x_{3}\right)$ and angle of welding $\left(x_{4}\right)$, (IFs) and air velocity of nozzles $y$ (THEN) are described by 16 rules as show in Fig. 3. The fuzzy logic of these rules generates fuzzy outputs by using the max-min compositional operation. Then the fuzzy air velocity of nozzles $\left(\mu_{V_{i}}(y)\right)$ can be represented as

$$
\begin{aligned}
\mu_{V_{i}}(y)= & \left(\mu_{A_{i}}^{1}\left(x_{1}\right) \wedge \mu_{B_{i}}^{1}\left(x_{2}\right) \wedge \mu_{C_{i}}^{1}\left(x_{3}\right) \wedge \mu_{D_{i}}^{1}\left(x_{4}\right) \vee\right. \\
& \ldots\left(\mu_{A_{i}}^{n}\left(x_{1}\right) \wedge \mu_{B_{i}}^{n}\left(x_{2}\right) \wedge \mu_{C_{i}}^{n}\left(x_{3}\right) \wedge \mu_{D_{i}}^{n}\left(x_{4}\right)\right)
\end{aligned}
$$

where $\wedge$ and $\vee$ are the minimum and maximum operation respectively. $A_{i}, B_{i}, C_{i}, D_{i}$ and $V_{i}$ are fuzzy subsets described by the membership functions, i.e., $\mu_{A_{i}}, \mu_{B_{i}}, \mu_{C_{i}}, \mu_{D_{i}}, \mu_{V_{i}}$ Generally, the fuzzy output is a linguistic variable which needs to be transformed to the crisp variable during the defuzzification process. For this study, the center of gravity method is applied to transform the fuzzy inference output into crisp values of air velocity of nozzle, $y^{*}$. Define rule number as $n$. The crisp values of air velocity of nozzle are calculated as

$$
y^{*}=\frac{\sum_{n=1}^{16} y\left(\mu_{V_{i}}^{n}(y)\right)}{\sum_{n=1}^{16} \mu_{V_{i}}^{n}(y)} \text { for } i=1,2, \ldots, n
$$

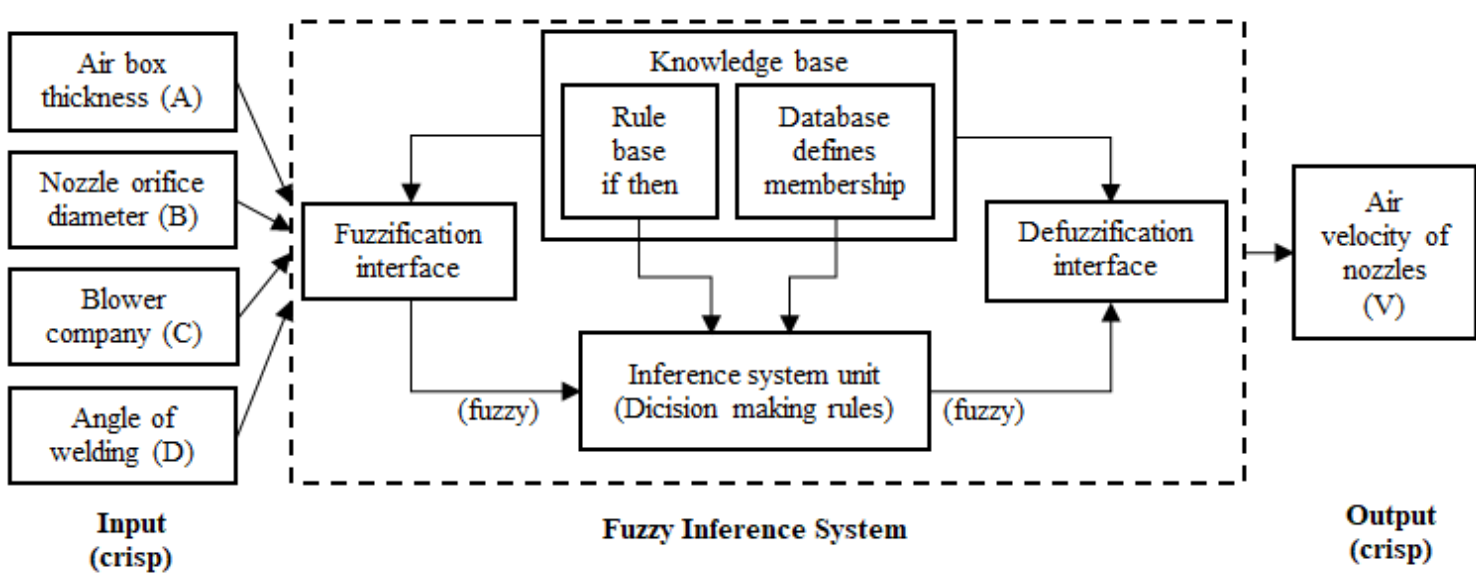

\begin{tabular}{|c|c|c|c|c|}
\hline Fuzzy parameters & Variables & "Universe of discourse & Membership functions & Linguistic value* \\
\hline \multirow[t]{4}{*}{ Input } & air box thickness $\left(\mu_{A_{i}}\right)$ & {$[250,300]$} & {$[250,275,300]$} & L, H \\
\hline & $\begin{array}{l}\text { nozzle orifice diameter } \\
\qquad\left(\mu_{B_{i}}\right)\end{array}$ & {$[25,27]$} & {$[25,26,27]$} & $\mathrm{L}, \mathrm{H}$ \\
\hline & blower company $\left(\mu_{C_{i}}\right)$ & {$[0,1]^{* *}$} & {$[0,1]$} & $\mathrm{L}, \mathrm{H}$ \\
\hline & angle of welding $\left(\mu_{D_{i}}\right)$ & {$[62,70]$} & {$[62,66,70]$} & L, H \\
\hline Output & air velocity of nozzles $\left(\mu_{V_{i}}\right)$ & {$[25,31]$} & {$[25.0,26.5,28.0,29.5,31.0]$} & VL, L, M, H, VH \\
\hline
\end{tabular}

Fig. 1. A scheme of clean room fuzzy inference system.

TABLE I: DESCRIPTION OF FUZZY INPUTS AND FUZZY OUTPUT

* VL = Very low, $\mathrm{L}=$ Low, $\mathrm{M}=$ Medium, $\mathrm{H}=$ High, $\mathrm{VH}=$ Very High ** $0=$ company $\mathrm{A}, 1=$ company $\mathrm{B}$

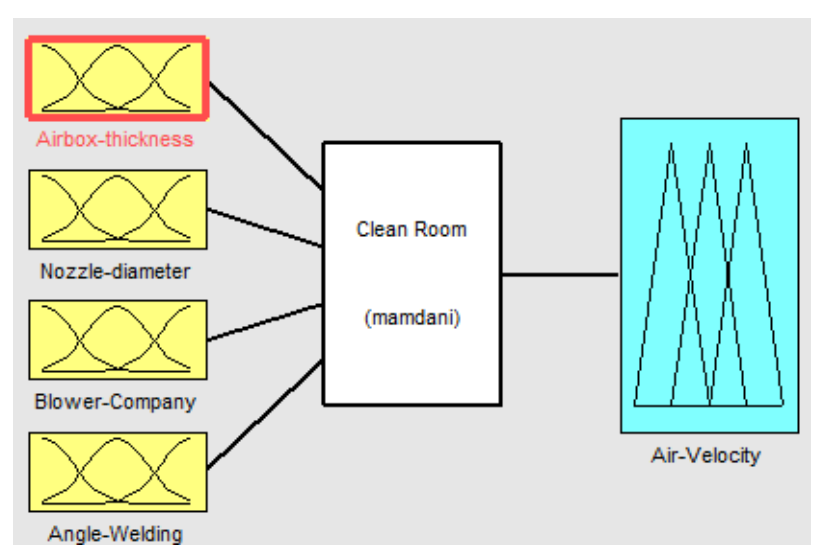

Fig. 2. Clean room fuzzy inference system.

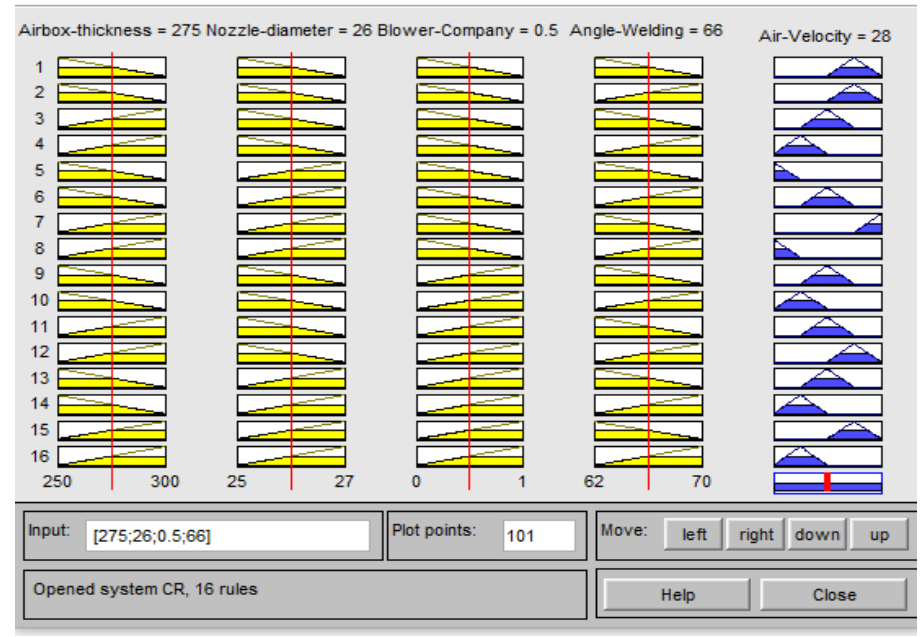

Fig. 3. Rule base view of clean room fuzzy inference system. 


\section{DESIGN OF EXPERIMENT AND APPLICATIONS}

Design of experiment (DOE) is an experiment by adjusting input variables or factors to determine the significant factors involved with changes in responses in the process of interest [8]. Input variables can be classified into two types: controllable variables and uncontrollable variables. Experiment design usually done in order. The first experiment is conducted to screen variables and find key variables from all controllable variables in the experiment. The next experiment is proposed to choose an appropriate level of variables affecting the outcome closest to the target. A factorial experiment is an experiment capable of conducting multifactor experiments. Factorial experiments can be classified into two types, full factorial experiments and fractional factorial experiments. Based on the analysis of variance (ANOVA), the impact analysis of the main factors and the interactions are considered by starting with considering interactions. If the interactions are significant, main factors related to the interactions will not be considered. The regression model of a $2^{4}$ factorial design can be described as:

$$
\begin{aligned}
\hat{Y}= & \hat{\beta}_{0}+\hat{\beta}_{i} A_{i}+\hat{\beta}_{j} B_{j}+\hat{\beta}_{k} C_{k}+\hat{\beta}_{l} D_{l}+\hat{\beta}_{i j} A_{i} B_{j} \\
& +\hat{\beta}_{i j k} A_{i} B_{j} C_{k}+\hat{\beta}_{i j k l} A_{i} B_{j} C_{k} D_{l}+\varepsilon, \\
& i=1,2, \ldots, 4, j=1,2, \ldots, 4, k=1,2, \ldots, 4, l=1,2, \ldots, 4
\end{aligned}
$$

where $\hat{Y}$ is the response, $\hat{\beta}_{0}$ is the mean of all treatment combinations, $\hat{\beta}_{i}, \hat{\beta}_{j}, \hat{\beta}_{k}, \hat{\beta}_{l}, \hat{\beta}_{i j}, \hat{\beta}_{i j k}$, and $\hat{\beta}_{i j k l}$ are half of the effect computed according to main effects, $A_{i}, B_{j}, C_{k}$, and $D_{l}$ are coded variables that describe main effects and take on values between -1 and +1 , and $\varepsilon$ is a random error term. The random error terms are supposed to have a normal distribution, a constant variance, and are independent [9]. Many researchers applied DOE in choosing appropriate parameters in manufacturing industries [10]-[12].

For this study, DOE is applied to study for selecting controllable factors affecting air velocity coming out of the nozzles. The $2^{4}$ factorial design technique was utilized for the experiments. For four factors, the design needs 16 runs with 3 replicates, which are entirely 48 runs as displayed in Table 2.

TABLE II: $2^{4}$ FACTORIAL EXPERIMENTAL DESIGNED OF AIR VELOCITY OF NOZZLES

\begin{tabular}{cccccccc}
\hline $\begin{array}{c}\text { Run } \\
\text { order }\end{array}$ & $\begin{array}{c}\text { Air box } \\
\text { thickness } \\
(A)\end{array}$ & $\begin{array}{c}\text { Nozzle } \\
\text { orifice } \\
\text { diameter } \\
(B)\end{array}$ & $\begin{array}{c}\text { Blower } \\
\text { company } \\
(C)\end{array}$ & $\begin{array}{c}\text { Angle of } \\
\text { welding } \\
(D)\end{array}$ & & Air velocity of nozzles (Replicate) \\
\hline 1 & 250 & 25 & A & 62 & 30.11 & 29.62 & 29.43 \\
2 & 250 & 25 & A & 70 & 28.13 & 28.15 & 30.64 \\
3 & 300 & 25 & A & 62 & 26.41 & 27.69 & 28.54 \\
4 & 300 & 25 & A & 70 & 26.08 & 29.32 & 25.89 \\
5 & 250 & 27 & A & 62 & 25.96 & 25.38 & 27.87 \\
6 & 250 & 27 & A & 70 & 28.59 & 27.70 & 28.00 \\
7 & 300 & 27 & A & 62 & 30.25 & 28.93 & 30.74 \\
8 & 300 & 27 & A & 70 & 25.84 & 26.58 & 26.17 \\
9 & 250 & 25 & B & 62 & 27.63 & 28.92 & 27.88 \\
10 & 250 & 25 & B & 70 & 27.65 & 26.54 & 26.28 \\
11 & 300 & 25 & B & 62 & 27.01 & 28.62 & 28.23 \\
12 & 300 & 25 & B & 70 & 29.98 & 29.77 & 30.43 \\
13 & 250 & 27 & B & 62 & 28.43 & 28.47 & 26.99 \\
14 & 250 & 27 & B & 70 & 26.50 & 26.09 & 27.45 \\
15 & 300 & 27 & B & 62 & 28.63 & 27.47 & 29.66 \\
16 & 300 & 27 & B & 70 & 25.92 & 28.82 & 26.40 \\
\hline
\end{tabular}

\section{RESULTS}

The data obtained from the experiment were analysed using the Minitab Release 15 program. Experiment accuracy is shown in Fig. 4. According to the consideration of normal probability plot of the residuals, that data were normally distributed. Fig. 5 shows a normal probability plot of the standardized effects. The impact values of point $B$ (nozzle orifice diameter), $D$ (angle of welding), interaction of $A C$, $A B C, A B D$ and $A C D$ indicated that they were influenced responsive factors with statistical significance (0.05). The experimental regression model has been constructed as

$$
\begin{aligned}
\hat{Y}= & 27.954-0.3356 B-0.3323 D+0.401 A C \\
& -0.486 A B C-0.5906 A B D+0.5215 A C D
\end{aligned}
$$

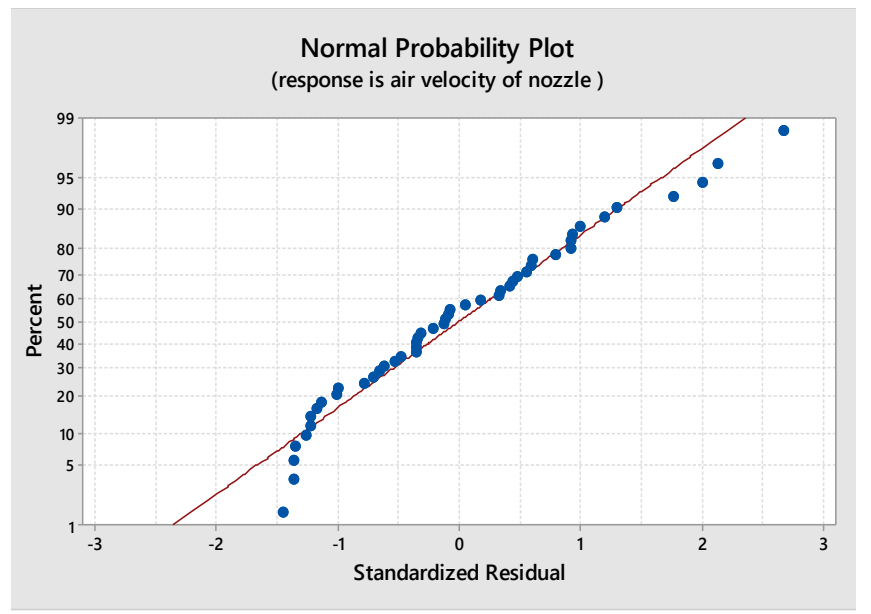

Fig. 4. Normal probability plot. 


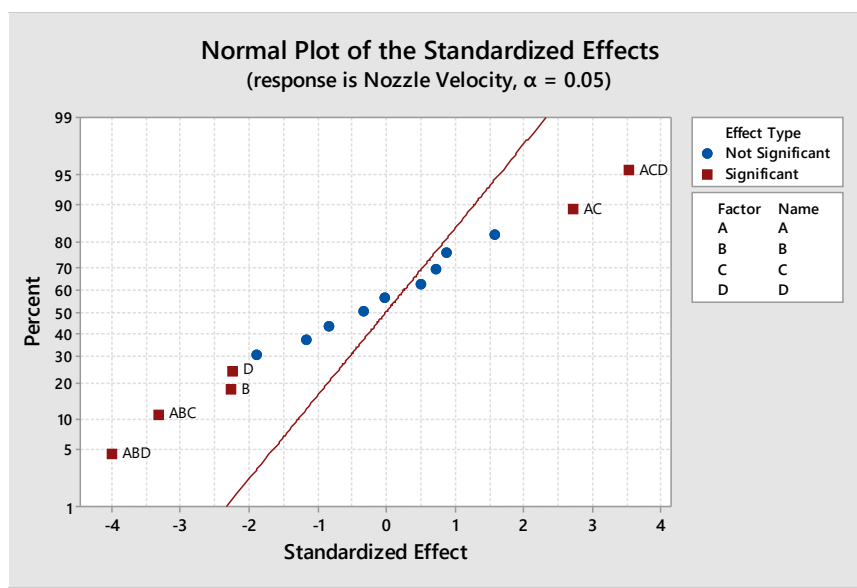

Fig. 5. Normal plot for air velocity of nozzles.

A factor with p-value $<0.05$ was considered statistically significant with a $95 \%$ confidence interval. For analysis of variance in Fig. 6, significant parameters were nozzle orifice diameter, and angle of welding to divert wind direction. A graphical representation of the main effect plots and the interaction plots are shown in Fig. 7 and Fig. 8, respectively.

\begin{tabular}{|c|c|c|c|c|}
\hline \multicolumn{5}{|l|}{ Analysis of Variance } \\
\hline Source & DF Adj SS & Adj MS & F-Value & P-Value \\
\hline Model & $15 \quad 69.362$ & 24.6241 & 14.47 & 0.000 \\
\hline Linear & $\begin{array}{lll}4 & 11.227 & 2\end{array}$ & 2.8067 & $2.71 \quad 0 .($ & 047 \\
\hline A & 0.540 & 0.5404 & $4 \quad 0.52$ & 0.475 \\
\hline B & 5.340 & 5.3398 & 35.16 & 0.030 \\
\hline $\mathrm{C}$ & 0.114 & 0.1138 & 0.11 & 0.742 \\
\hline $\mathrm{D}$ & 5.233 & 5.2330 & 5.05 & 0.032 \\
\hline 2-Way Interactions & $\begin{array}{lll}6 & 14.955 \quad 2\end{array}$ & 2.4925 & 2.410 .0 & 049 \\
\hline$A * B$ & 2.570 & 2.5697 & $7 \quad 2.48$ & 0.125 \\
\hline$A * C$ & 7.656 & 7.6560 & 7.39 & 0.010 \\
\hline$A * D$ & 0.727 & 0.7270 & 0.70 & 0.408 \\
\hline$B * C$ & 0.001 & 0.0009 & 0.00 & 0.976 \\
\hline$B * D$ & 3.726 & 3.7256 & 3.60 & 0.067 \\
\hline$C^{*} \mathrm{D}$ & 0.276 & 0.2757 & 0.27 & 0.609 \\
\hline 3-Way Interactions & $\begin{array}{lll}4 & 42.398 & 1\end{array}$ & 10.5995 & 10.240. & 000 \\
\hline $\mathrm{A} * \mathrm{~B} * \mathrm{C}$ & $\begin{array}{lll}1 & 11.417 & 1\end{array}$ & 11.4170 & 11.030. & 002 \\
\hline$A * B * D$ & $\begin{array}{lll}1 & 16.597 & 1\end{array}$ & 16.5973 & 16.030. & 000 \\
\hline$A * C * D$ & $\begin{array}{lll}1 & 12.959 & 1\end{array}$ & 12.9587 & 12.520. & 001 \\
\hline $\mathrm{B} * \mathrm{C} * \mathrm{D}$ & 1.425 & 1.4248 & 1.38 & 0.249 \\
\hline 4-Way Interactions & 0.782 & 0.7825 & 0.76 & 0.391 \\
\hline $\mathrm{A}^{*} \mathrm{~B} * \mathrm{C} * \mathrm{D}$ & 0.782 & 0.7825 & 0.76 & 0.391 \\
\hline Error & 33.133 & 31.0354 & & \\
\hline Total & 102.49 & & & \\
\hline
\end{tabular}

Fig. 6. Analysis of variance from Minitab program.

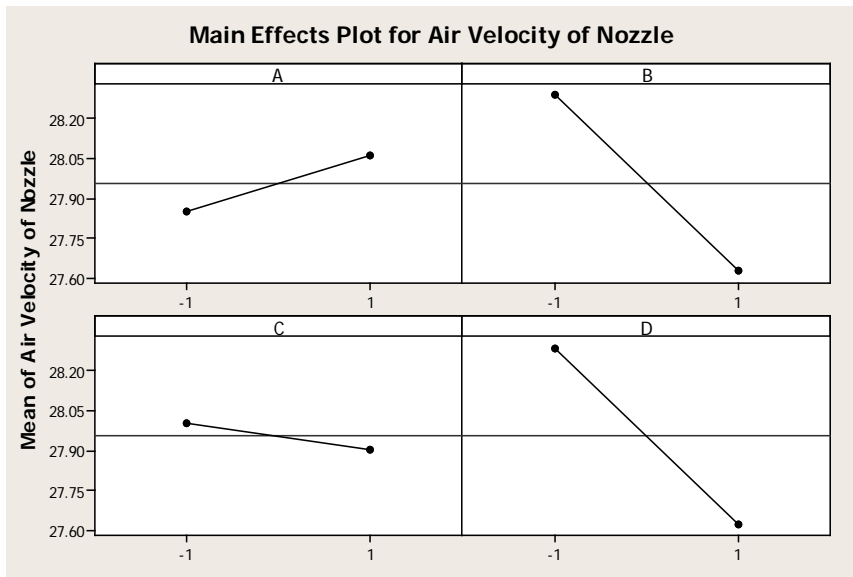

Fig. 7. Main effect plot of results.
The models can be assessed with the statistical parameters such as the coefficient of determination $\left(R^{2}\right)$. The results of $R^{2}$ for FIS and DOE are achieved 0.9177 and 0.8541 respectively. The FIS model represented with better results than the DOE model. The actual results of air velocity of nozzles were compared with FIS model and DOE model as shown in Fig. 9.

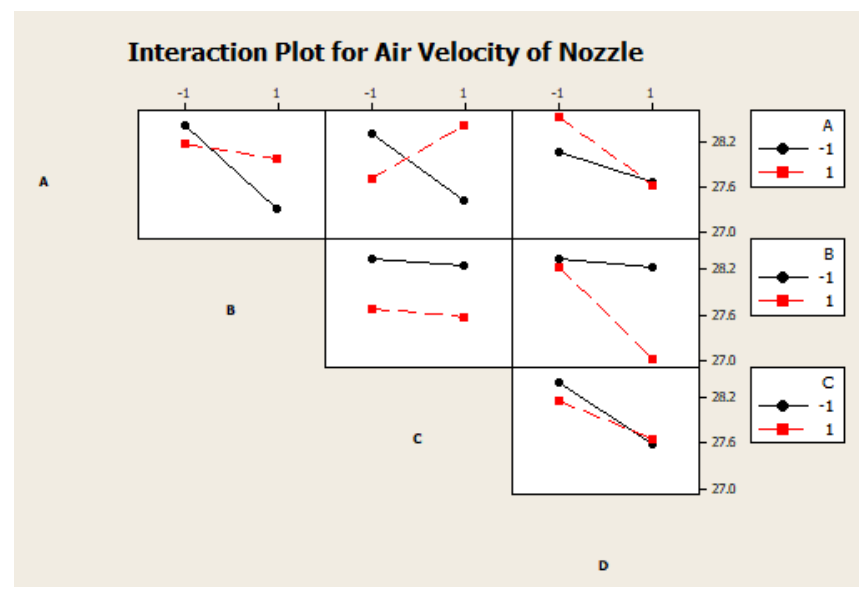

Fig. 8. Interaction plot of results.

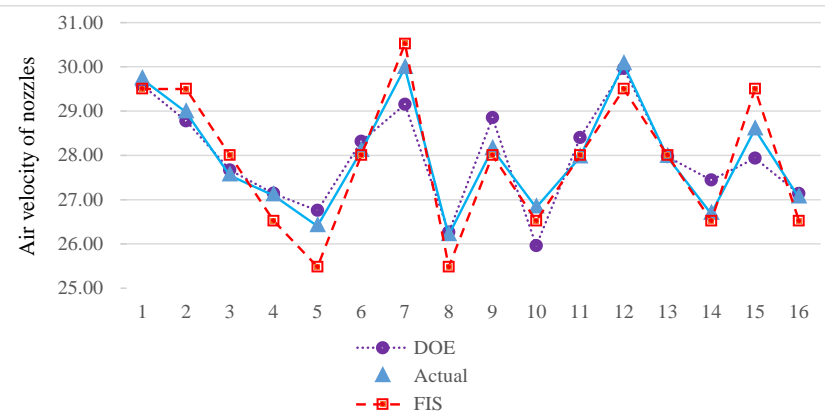

Fig. 9. The comparison of FIS, DOE and actual results of air velocity of nozzles.

\section{CONCLUSION}

A comparative study of FIS model and DOE model were implemented for determining of air velocity of nozzles of the air shower pass box production process with uncertain conditions. The results indicated that FIS model accomplished better performance than the DOE model. The most appropriate levels of setting achieved by the FIS model by setting the thickness of the air box at $300 \mathrm{~mm}$, nozzle orifice diameter of $27 \mathrm{~mm}$, blower from company A, and angle of welding at 62 degrees. FIS is a valuable experimental strategy for designing and conducting experiments. Although the DOE model presented less performance, but it indicated the interaction and the main factors which influencing to the outcome. For future study, other artificial intelligent techniques such as artificial neural network or adaptive neuro-fuzzy inference system would be suggested to implement in the product design process.

\section{REFERENCES}

[1] B. Ljungqvist and B. Reinmüller, Clean Room Design: Minimizing Contamination through Proper Design, Boca Raton, Florida: Interpharm/CRC Press, 2002.

[2] H. Singh, J. Vidja, M. Agrawal, R. K. Sharma, and S. Pathak, "Execution \& qualification of heating, ventilation and air conditioning 
system," Journal of Pharmaceutical Research \& Education, vol. 1, no. 1, pp. 172-195, 2016

[3] O. Castillo and P. Melin, Type-2 Fuzzy Logic Theory and Applications, Berlin: Springer-Verlag, 2008.

[4] L. E. Vafaei and M. Sah, "Predicting efficiency of flat-plate solar collector using a fuzzy inference system,” Procedia Computer Science, vol. 120, pp. 221-228, 2017.

[5] Y. K. Kang, H. Kim, G. Heo, and S. Y. Song, "Diagnosis of feedwater heater performance degradation using fuzzy inference system," Expert Systems with Applications, vol. 69, pp. 239-246, 2017.

[6] P. Aengchuan and B. Phruksaphanrat. (April 2018). Comparison of fuzzy inference system (FIS), FIS with artificial neural networks (FIS + ANN) and FIS with adaptive neuro-fuzzy inference system (FIS + ANFIS) for inventory control. Journal of Intelligent Manufacturing. [Online]. 29(4). pp. 905-923. Available: https://doi.org/10.1007/s10845-015-1146-1.

[7] E. H. Mamdani and S. Assilian, "An experiment in linguistic synthesis with fuzzy logic controller,” International Journal of Man-Machine Studies, vol. 7, pp. 1-13, 1975.

[8] D. C. Montgomery, Design and Analysis of Experiments, 8th ed. New Jersey: John Wiley \& Sons, Inc., 2013.

[9] K. Kazemi, B. Zhang, L. M. Lye, Q. Cai, and T. Cao, "Design of experiment (DOE) based screening of factors affecting municipal solid waste (MSW) composting," Waste Management, vol. 58, pp. 107-117, 2016.

[10] C. M. Madsen, K. I. Feng, A. Leithead, N. Canfield, S. A. Jorgensen, A. Müllertz, and T. Rades, "Effect of composition of simulated intestinal media on the solubility of poorly soluble compounds investigated by design of experiments," European Journal of Pharmaceutical Sciences, vol. 111, pp. 311-319, 2018.

[11] K. Vachhani, A. Pagotto, Y. Wang, C. Whyne, and D. Nam, “Design of experiments confirms optimization of lithium administration parameters for enhanced fracture healing," Journal of Biomechanics, vol. 66, pp. 153-158, 2018.

[12] Q. Wei, C. M. Keck, and R. H. Müller, "Solidification of hesperidin nanosuspension by spray drying optimized by design of experiment (DoE)," Drug Development and Industrial Pharmacy, vol. 44, no. 1, pp. 1-12, 2018.

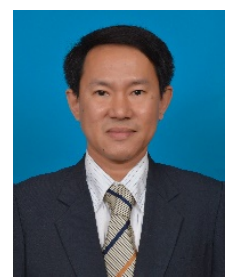

Prasert Aengchuan received a bachelor degree in mechanical engineering from Mahidol University, Thailand in 1994. He obtained his master degree in industrial system engineering from Asian Institute of Technology, Thailand in 1998. He also received his Ph.D. in industrial engineering from Thammasat University, Thailand in 2015. Currently, he works as a lecturer in School of Manufacturing Engineering, Institute of Engineering, Suranaree University of Technology, Thailand. His research interests are fuzzy logic, adaptive neuro-fuzzy inference system, artificial neural network for industrial application and experimental designs.

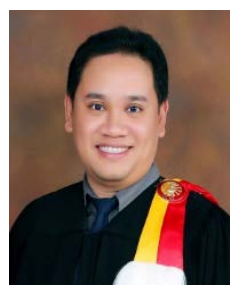

Pasura Aungkulanon received a bachelor degree in industrial engineering from Kasetsart University Thailand in 2003. Then, he continued higher education. He obtained his master degree and Ph.D. in industrial engineering from Thammasat University, Thailand in 2010 and 2016 respectively. Currently, he works as a lecturer at the Department of Industrial Engineering, Faculty of Engineering, Srinakharinwirot University, Thailand. His research areas include operational research, artificial intelligence, metaheuristic methods, logistics and supply chain system. 